\title{
INTELLECTUAL CAPITAL DISCLOSURE BASED STAKEHOLDERS PADA PERBANKAN INDONESIA
}

\author{
Enok Nurhayati dan Lia Uzliawati \\ Fakultas Ekonomi dan Bisnis Universitas Sultan Ageng Tirtayasa \\ uzliawati@unirta.ac.id
}

\begin{abstract}
This study analyses Indonesia stekholders viewpoints on Intellectual Capital Disclosure items using Intellectual Capital Disclosure Index. Respodents on this research is narrow financial based stakeholders. Respondents rating showed high average scores of 5,88 with all items. These score indicated that there is clear expectation of stakeholders for Indonesian banking sector to disclosed all of items. The weighted Indonesia Intellectual Capital Disclosure Index on Bankingis developed based on insight of survey responden which better reflect the importance of key stakeholders demand for Intellectual capital disclosure in Indonesia Banking Sector.
\end{abstract}

Keywords:Indeks, intellectual capital disclosure, intellectual capital disclosure index, narrow financialbased stakeholder, Banking.

\begin{abstract}
Abstrak: Penelitian ini menganalisis sudut pandang pemegang saham Indonesia terhadap item Pengungkapan Modal Intelektual dengan menggunakan Intellectual Capital Disclosure Index. Respoden pada penelitian ini adalah pemangku kepentingan berbasis keuangan yang sempit. Peringkat responden menunjukkan nilai rata-rata yang tinggi sebesar 5,88 dengan semua item. Skor ini mengindikasikan adanya harapan yang jelas dari pemangku kepentingan terhadap sektor perbankan Indonesia untuk mengungkapkan semua item. Indeks Keterbukaan Informasi Intelektual Indonesia tertimbang tentang Perbankan dikembangkan berdasarkan wawasan responden survei yang lebih mencerminkan pentingnya permintaan stakeholder utama untuk keterbukaan modal Intelektual di Sektor Perbankan Indonesia.
\end{abstract}

Kata kunci: Indeks, keterbukaan modal intelektual, indeks pengungkapan intellectual capital, pemangku kepentingan berbasis keuangan yang sempit, Perbankan.

\section{PENDAHULUAN}

Penelitian ini bertujuan untuk mengidentifikasitingkat permintaan (demand)atas item-item intellectual capital disclosure pada sektor perbankan. Pengungkapan (disclosure) yang dilakukan oleh perusahaan adalah alat yang penting untuk mengkomunikasikan kinerja ekonomi. Disclosure meliputi ketersediaan informasi keuangan dan non keuangan berkaitan dengan interaksi organisasi yang dibuat dalam laporan tahunan perusahaan (annual report) (Guthrie dan Parker, 1990).

Intellectual capital di dalam laporan tahunan merupakan sesuatu yang masih bersifat voluntary atau sukarela, sehingga ada tidaknya pengungkapan dalam ini dalam laporan tahunan bergantung pada kebijakan perusahaan masing-masing.

Intellectual capital telah menjadisuatuprioritasutama manajemendalam mencapai visi misi perusahaan. Eccles, Herz, Keegan, dan Philips (2001) memaparkansurvey 
yang dilakukan oleh Price Waterhous Coopers (PWC) mengenai jenis-jenis informasi yang dibutuhkan oleh investor. Hasil survei menunjukan bahwa dari sepuluh tipe informasi yang paling penting bagi investor tiga diantaranya adalah informasi finansial, dua tipe berupa data internal perusahaan (strategic direction dan competitive landscape), lima tipe lainnya adalah intangible (market growth, experiance of management team, market size, market share, speed to market).

Price Waterhous Coopers mengidentifikasikan bahwa intellectual capital disclosuremerupakan strategi yang penting bagi perusahaan. Tipe informasi yang paling banyak dipertimbangkan oleh investor pada kenyataannya tidak diungkapkan oleh manajerdalam laporan keuangan. Hal ini kemudian menimbulkan information gap antara investor dan manajemen (Bozzolan,Favotto,danRicceri, 2003). Hasil penelitian tersebut dapat disimpulkan bahwa intellectual capital disclosure penting untuk diungkapkan oleh perusahaan mengingat permintaan stakeholders juga tinggi. Kesadaran perusahaan akan pentingnya value creationse bagai salah satu pembentuk company long term value mendorong perusahaan untuk melakukan intellectual capital disclosure kedalam annual report,sebagai salah satu penawaran yang diberikan oleh perusahaan.

\section{KAJIAN TEORI}

Intellectual Capita IDisclosure. Beberapa peneliti telah banyak mengemukakan pendapat mengenai komponen modal intelektual. Edvinson dan Malone (1997) membagi intelektual modalke 2 komponen; sumber daya manusia dan struktural modal. Ross dan Ross (1997) mengelompokkan intelektual modal intellectual capital ketiga aspek; sumber daya manusia, organisasi (struktural) modal, dan modal relasional.

Literatur tentang Intellectual Capital Disclosure (ICD) telah berkembang pesat secara internasional (Guthrie dan Petty, 2000; Bozzolan et al., 2003; Bontis, 2003; Abeysekera dan Guthrie, 2005; Cerbioni dan Parbonetti, 2007; Li et al., 2006, 2008; Abeysekera, 2010; Yi dan Davey, 2010; Hidalgo, 2011; Ghazali dan Haji, 2013). Pengungkapan informasi mengenai Intellectual Capital perusahaan bertujuan sebagai media untuk mengkomunikasikan kemampuan perusahaan dalam pembentukan value added tidak hanya berdasarkan physical capital atau financial capital, melainkan berdasarkan intangible resources, seperti market growth, quality of the management team, customers relationship, dan lain-lain (Eccles et al., 2001).

Penelitian mengenai Intellectual Capital Disclosure merupakan area eksplorasi penelitian yang sangat besar karena konsep Intellectual Capital sendiri merupakan konsep yang baru. Kebanyakan penelitian mengenai Intellectual Capital Disclosure masih bersifat cross sectional, misalnya: Bozzolan et al., (2003) berusaha meneliti tingkat keluasaan Intellectual Capital Disclosure di Italia tahun 2001. Firer dan William (2003) mengidentifikasikan 390 perusahaan listed di Singapura tahun 2000.

Penelitian mengenai Intellectual Capital Disclosure juga dilakukan oleh Guthrie dan Petty (2000) yang melakukan penelitian terhadap 20 perusahaan di Australia yang telah terdaftar di bursa efek. Harisson dan Sullivan (2000) mengemukakan bahwa kesuksesan perusahaan sangat dipengaruhi oleh usaha-usaha perusahaan untuk memaksimalkan nilai-nilai dalam intellectual capital. Perusahaan yang menyajikan Intellectual Capital Disclosure memberikan informasi lebih baik kepada stakeholders sebagai pedoman untuk pengambilan keputusan yang lebih baik. 
Stakeholders Theory. Stakeholders theory mengatakan bahwa perusahaan bukanlah entitas yang hanya beroperasi untuk kepentingannya sendiri namun harus memberikan manfaat bagi stakeholdernya. Dengan demikian, keberadaan suatu peusahaan sangat dipengaruhi oleh dukungan yang diberikan oleh stakeholders kepada perusahaan tersebut.

Intellectual Capital Disclosure dianggap sebagai bagian dari komunikasi perusahaan dengan stakeholder-nya. Stakeholder pada dasarnya dapat mengendalikan atau memiliki kemampuan untuk mempengaruhi pemakain sumber-sumber ekonomi yang digunakan perusahaan. Power stakeholders ditentukan oleh besar kecilnya power yang mereka miliki atas sumber tersebut. Power tersebut dapat berupa kemampuan untuk membatasi pemakai sumber ekonomi yang terbatas (modal dan tenaga kerja), akses terhadap media yang berpengaruh, kemampuan untuk mengatur perusahaan, atau kemampuan untuk mempengaruhi konsumsi atas barang atau jasa yang dihasilkan perusahaan (Deegan, 2006).

Ketika stakeholder mengendalikan sumber ekonomi yang penting bagi perusahaan, maka perusahaan akan beraksi dengan cara yang memuaskan keinginan stakeholder (Ullman, 1985). Selanjutnya, Ullman (1985) mengatakan bahwa organisasi akan memilik stakeholder yang dipandang penting, dan mengambil tindakan yang dapat menghasilkan hubungan harmonis antara perusahaan dengan stakeholder-nya.

Narrow FinancialBased Stakeholders. Harisson dan Freeman (1999); Brown dan Tower (2007), stakeholder diklasifikasikan kedalam dua sudut pandang, yaitu: 1) Strategic management (financial focus). Clarkson membagi strategic management ke dalam dua kelompok, berdasarkan pengaruhnya terhadap eksistensi perusahaan yaitu primary stakeholders dan secondary stakeholders. Primary stakeholders merupakan kelompok yang memiliki tingkat kekuatan finansial yang tinggi dengan perusahaan dan berpengaruh langsung terhadap kelangsungan perusahaan, misalnya kreditor. Sedangkan secondary stakeholders adalah kelompok yang memiliki hubungan saling mempengaruhi tetapi tidak berpengaruh langsung secarafinansial, misalnya media, akademisdan lingkungan. 2) Moralbased (broaderfocus). Brown dan Tower (2007), mengelompokkan moral based ke dalam empat kelompok stakeholder, yaitu interestbased, rightbased, dutybased, dan virtue based stakeholder. Interest based atau narrow financial based stakeholder merupakan kelompok yang lebih fokus pada cost dan benefit, atau memaksimalisasi laba.

Penelitian ini menggunakan prespektif interest based atau narrow financial based stakeholders karena kelompok ini lebih berfokus di bidang financial dan memiliki hubungan yang erat terhadap kelangsungan hidup suatu perusahaan. Narrow stakeholders merupakan pengguna yang berhubungan langsung dan sangat dominan dalam proses bisnis perusahaan (Suhardjanto, Brown dan Tower, 2007).

\section{METODE}

Populasi penelitian ini adalah 36 bank yang terdaftar di BEI. Sampel yang digunakan melalui metode purposive. Responden kuestioner penelitian ini adalah narrow financial based stakeholders dengan jumlah responden adalah sebesar sampel 96. Responden penelitian ini bertujuan untuk mengevaluasi relevansi dari 35 item ICD melalui kuestioner dengan skala Likert 1-7. Skor (1) menggambarkan sangat tidak penting sekali sedangkan Skor (7) sangat penting sekali. 
Teknik pengukuran yang dilakukan dengan menggunakan ukuran disclosure scoring. Item yang memperoleh skor/bobot tertinggi mencerminkan Intellectual capital tersebut paling sering diinformasikan den paling tinggi diminta oleh stakeholder dan begitu pula sebaliknya.

Bobot skor yag digunakan dalam penelitian ini merupakan framework Sveiby (1997), Edvinsson dan Malone (1997), Brooking (1996), Gutheri dan Petty (2000), dan Bozzolan (2003). Yang di modifikasi melaluiitem-item yang telah menjadi mandatory disclosure oleh Bapepam, dan UU PT yang terdapat di Indonesia yang diberlaku pada sektor perbankan. Sehingga, diperoleh item-item Intellectual Capital Disclosure yang bersifat voluntary disclosure. Selanjutnya, item-item Intellectual Capital Disclosure tersebut dilakukan pembobotan (weighted) dengan menggunakan narrow financial based stakeholders yang terdiri dari primary stakeholders dan secondary stakeholders. Metode skor yang digunakan pada penelitian ini adalah weighted index, yaitu masing-masing item dalam Intellectual Capital Disclosure memiliki bobot skor tersendiri bergantung pada pengguna (users).

Penelitian ini melakukan split sampel yaitu dengan menggunakan ukuran perusahaan besar dan kecil yang ditentukan berdasarkan total aset yang dimiliki oleh perusahaan perbankan tersebut.

\section{HASIL DAN PEMBAHASAN}

Item-item Intellectual Capital Disclosure dilakukan pembobotan (weighted) dengan menggunakan narrow financial based stakeholders yang terdiri dari primary stakeholders dan secondary stakeholders. Penggunaan skor ini dipilih karena bobot skor yang diberikan akan sesuai dengan kepentingan dan kebutuhan users sehingga hasilnya diharapkan akan lebih tepat dan akurat (Oliveira, Rodrigues dan Craig, 2008). Berbeda user maka akan berbeda pula tingkat kepentingan atas item informasi yang dibutuhkannya (Oliveira et al., 2008).

Berdasarkan hasil weighted index tersebut dapat dilihat pada Tabel 1.

Tabel 1. Index ICD Perbankan Indonesia

\begin{tabular}{rlc}
\hline No. & \multicolumn{1}{c}{ Item ICD } & Index \\
\hline 1 & Service marks & 1,15 \\
2 & Trade dress & 1,15 \\
3 & Management philosophy & 1,09 \\
4 & Information systems & 1,09 \\
5 & Management processes & 1,04 \\
6 & Networking systems & 1,07 \\
7 & Research Project & 0,95 \\
8 & Organization Capital & 1,05 \\
9 & Process capital & 0,97 \\
10 & Financial relation & 0,99 \\
11 & corporate stratgies & 1,07 \\
12 & corporate method & 1,02 \\
13 & Sales tools & 1,06 \\
14 & Knowledge-based & 0,96 \\
15 & Expert networks and teams & 0,98 \\
\hline
\end{tabular}




\begin{tabular}{rlc}
\hline No. & \multicolumn{1}{c}{ Item ICD } & Index \\
\hline 16 & Corporate values & 1,12 \\
17 & intangible asset & 1,02 \\
18 & Customers & 1,15 \\
19 & customers satisfaction & 1,13 \\
20 & customers penetration and breadth & 1,03 \\
21 & Baclog orders & 1,04 \\
22 & Business collaborations & 1,03 \\
23 & Reapet business & 0,96 \\
24 & Favourable contracts & 0,91 \\
25 & Financial well beeing & 0,87 \\
26 & Price sensitivity & 0,87 \\
27 & Know-how & 0,94 \\
28 & Vocational qualification & 0,94 \\
29 & Work-related knowledge & 0,94 \\
30 & Psychometrics assesment & 0,85 \\
31 & Models and framework & 0,86 \\
32 & Cultural diversity & 0,80 \\
33 & Entrepreneurial spirit & 0,99 \\
34 & Reactive ability & 0,99 \\
35 & Changebility & 0,94 \\
& TOTAL & 35,00 \\
\hline
\end{tabular}

Survei kuestioner dengan menggunakan Index ICD Perbankan Indonesia tersebut di atas maka diperoleh skor dan rating masing-masing item ICD. Tabel 2. Di bawah ini menggambarkan Nilai index ICD berdasakarkan narrow staekholder.

Tabel 2. Nilai Index berdasarkan User

\begin{tabular}{clcccc}
\hline No. & \multicolumn{1}{c}{ Item Icd } & Score & Mean & Bobot \% & $\begin{array}{c}\text { Icd } \\
\text { Index }\end{array}$ \\
\hline 1 & Service marks & 216 & 6,75 & 3,28 & 1,15 \\
2 & Trade dress & 216 & 6,75 & 3,28 & 1,15 \\
3 & Customers & 216 & 6,75 & 3,28 & 1,15 \\
4 & customers satisfaction & 212 & 6,63 & 3,22 & 1,13 \\
5 & Corporate values & 210 & 6,56 & 3,19 & 1,12 \\
6 & Management philosophy & 205 & 6,41 & 3,12 & 1,09 \\
7 & Information systems & 204 & 6,38 & 3,10 & 1,09 \\
8 & corporate stratgies & 202 & 6,31 & 3,07 & 1,07 \\
9 & Networking systems & 201 & 6,28 & 3,05 & 1,07 \\
10 & Sales tools & 199 & 6,22 & 3,02 & 1,06 \\
11 & Organization Capital & 197 & 6,16 & 2,99 & 1,05 \\
12 & Management processes & 195 & 6,09 & 2,96 & 1,04 \\
13 & Baclog orders & 195 & 6,09 & 2,96 & 1,04 \\
14 & customers penetration and & 194 & 6,06 & 2,95 & 1,03
\end{tabular}


Nurhayati dan Uzliawati: Intellectual Capital Disclosure Based Stakeholders...

\begin{tabular}{|c|c|c|c|c|c|c|}
\hline No. & Item Icd & Score & Mean & Bobot $\%$ & Icd Index & No. \\
\hline 15 & Business collaborations & & 194 & 6,06 & 2,95 & 1,03 \\
\hline 16 & corporate method & & 191 & 5,97 & 2,90 & 1,02 \\
\hline 17 & intangible asset & & 191 & 5,97 & 2,90 & 1,02 \\
\hline 18 & Financial relation & & 187 & 5,84 & 2,84 & 0,99 \\
\hline 19 & Entrepreneurial spirit & & 186 & 5,81 & 2,83 & 0,99 \\
\hline 20 & Reactive ability & & 186 & 5,81 & 2,83 & 0,99 \\
\hline 21 & Expert networks and teams & & 185 & 5,78 & 2,81 & 0,98 \\
\hline 22 & Process capital & & 183 & 5,72 & 2,78 & 0,97 \\
\hline 23 & Reapet business & & 181 & 5,66 & 2,75 & 0,96 \\
\hline 24 & Knowledge-based & & 180 & 5,63 & 2,74 & 0,96 \\
\hline 25 & Research Project & & 178 & 5,56 & 2,71 & 0,95 \\
\hline 26 & Vocational qualification & & 177 & 5,53 & 2,69 & 0,94 \\
\hline 27 & Work-related knowledge & & 177 & 5,53 & 2,69 & 0,94 \\
\hline 28 & Changebility & & 177 & 5,53 & 2,69 & 0,94 \\
\hline 29 & Know-how & & 176 & 5,50 & 2,67 & 0,94 \\
\hline 30 & Favourable contracts & & 172 & 5,38 & 2,61 & 0,91 \\
\hline 31 & Financial well beeing & & 163 & 5,09 & 2,48 & 0,87 \\
\hline 32 & Price sensitivity & & 163 & 5,09 & 2,48 & 0,87 \\
\hline 33 & Models and framework & & 162 & 5,06 & 2,46 & 0,86 \\
\hline 34 & Psychometrics assesment & & 159 & 4,97 & 2,42 & 0,85 \\
\hline \multirow[t]{3}{*}{35} & Cultural diversity & & 150 & 4,69 & 2,28 & 0,80 \\
\hline & & TOTAL & 6580 & 205,63 & 100,00 & 35,00 \\
\hline & & MEAN & 188,00 & $\mathbf{5 , 8 8}$ & 2,86 & $\mathbf{1 , 0 0}$ \\
\hline
\end{tabular}

Berdasarkan Tabel 2 di atas menunjukan besarnya rerata kepentingan Intellectual Capital Disclosure menurut users yaitu sebesar 2,86\% (score $=188,00$ dan ICD index $=$ $1,00)$. Kisaran score setiap item tidak menunjukan perbedaan yang terlalu jauh, berkisar antara 150-216. Hal ini menunjukan bahwa rerata setiap item Intellectual Capital Disclosure menurut users memiliki tingkat kepentingan yang sama besarnya.

Terdapat beberapa item dengan nilai index kurang dari rerata yaitu: 1,00. Item-item tersebut antara lain: financial relation, entrepreunerial spirit, dan reactive ability $(0,99)$, item-item human capital (work-related knowledge, know-how, entrepreunerial spirit, change ability, psychometrics assessment, models and framework, cultural diversity, vocational qualification, process capital, dan lain-lain. Dapat disimpulkan bahwa itemitem tersebut dianggap tidak begitu penting, terutama dalam pengambilan keputusan bisnis jangka pendek. Investor masih memiliki kecenderungan mementingkan company performance dari segi angka-angka keuangan dibandingkan dengan sumber daya manusia yang dimiliki.

Secara garis besar dapat disimpulkan bahwa menurut users, Intellectual Capital Disclosure penting untuk diungkapkan dalam annual report. Hal tersebut ditunjukan dengan nilai mean sebesar 5,88 (dalam skala likert 7) yang berarti penting. Menurut users, Intellectual Capital Disclosure merupakan informasi penting yang berkaitan dengan aktivitas perusahaan serta dapat meningkatkan keuntungan perusahaan yang labanya 
dipengaruhi oleh item Intellectual Capital (Edvinson dan Sulivan, 1996). Selain itu, Price Waterhouse Coopers (PWC) menyatakan bahwa Intellectual Capital merupakan strategi penting bagi perusahaan dan merupakan informasi yang banyak dibutuhkan oleh investor. Tabel 3 berikut ini menggambarkan Frekuensi demand atas ICD berdasakarkan narrow staekholder pada Perbankan Indonesia secara keseluruhan.

Tabel 3. Frekuensi DemandIntellectual Capital DisclosurePerbankan Indonesia

\begin{tabular}{|c|c|c|}
\hline Item Intellectual Capital & Total sampel & $\%$ \\
\hline & 192 & \\
\hline Corporate values & 153 & 79,69 \\
\hline Information systems & 152 & 79,17 \\
\hline Organization Capital & 152 & 79,17 \\
\hline Financial relation & 150 & 78,13 \\
\hline Process capital & 147 & 76,56 \\
\hline Service marks & 145 & 75,52 \\
\hline intangible asset & 145 & 75,52 \\
\hline Trade dress & 140 & 72,92 \\
\hline corporate stratgies & 139 & 72,40 \\
\hline Customers & 138 & 71,88 \\
\hline Models and framework & 138 & 71,88 \\
\hline Entrepreneurial spirit & 138 & 71,88 \\
\hline Knowledge-based & 137 & 71,35 \\
\hline Sales tools & 136 & 70,83 \\
\hline corporate method & 134 & 69,79 \\
\hline customers satisfaction & 134 & 69,79 \\
\hline $\begin{array}{l}\text { customers penetration and } \\
\text { breadth }\end{array}$ & 134 & 69,79 \\
\hline Management processes & 132 & 68,75 \\
\hline Expert networks and teams & 132 & 68,75 \\
\hline Work-related knowledge & 128 & 66,67 \\
\hline Baclog orders & 117 & 60,94 \\
\hline Networking systems & 101 & 52,60 \\
\hline Management philosophy & 98 & 51,04 \\
\hline Know-how & 97 & 50,52 \\
\hline Business collaborations & 87 & 45,31 \\
\hline Cultural diversity & 87 & 45,31 \\
\hline Favourable contracts & 77 & 40,10 \\
\hline Vocational qualification & 77 & 40,10 \\
\hline Changebility & 72 & 37,50 \\
\hline Research Project & 66 & 34,38 \\
\hline
\end{tabular}




\begin{tabular}{lccc}
\hline Psychometrics assesment & 57 & 29,69 \\
Reactive ability & 53 & 27,60 \\
Reapet business & 48 & 25,00 \\
Price sensitivity & 45 & 23,44 \\
Financial well beeing & & 44 & 22,92 \\
& & & $\mathbf{2 0 4 6 , 8 8}$ \\
& Total & $\mathbf{5 8 , 4 8}$ \\
\hline
\end{tabular}

Tabel 3 di atas menunjukan pada perusahaan sektor perbankan secara menyeluruh, besarnya rerata kepentingan Intellectual Capital Disclosure menurut users yaitu sebesar $58,48 \%$. Hal ini menunjukan bahwa rerata setiap item Intellectual Capital Disclosure menurut users memiliki tingkat kepentingan yang sama besarnya.

Pada Sektor perbankan secara keseluruhan item Intellectual Capital yang sering diungkapkan setiap tahunnya pada annual report dengan prosentase pengungkapan sebesar 79, 69\% adalah corporate value. Corporate value berkaitan erat dengan pemberdayaan karyawan dalam suatu perusahaan. Corporate value merupakan nilai-nilai yang terdapat di dalam perusahaan yang dapat memotivasi karyawan guna terwujudnya tujuan perusahaan. Berdasarkan hal tersebut, pengenalan, penciptaan, dan pengembangan corporate value dalam suatu perusahaan multak diperlukan dalam rangka membangun perusahaan yang efektif dan efesien sesuai dengan visi dan misi yang hendak dicapai. Perusahaan yang tergolong dalam size kecil berdasarkan total asetnya Frekuensi demand atas ICD berdasakarkan narrow staekholder tergambarkan dalam Tabel. 4 berikut ini:

Tabel 4. Frekuensi pengungkapan setiap item Intellectual Capital

Perusahaan Size Kecil

\begin{tabular}{lcc}
\hline \multicolumn{1}{c}{ Item Intellectual Capital Disclosure } & Total sampel & \% \\
\hline & 121 & 77.69 \\
Corporate values & 94 & 76.86 \\
Information systems & 93 & 76.86 \\
Organization Capital & 93 & 75.21 \\
Financial relation & 91 & 73.55 \\
Process capital & 89 & 71.07 \\
Service marks & 86 & 71.07 \\
intangible asset & 86 & 70.25 \\
Customers & 85 & 70.25 \\
Entrepreneurial spirit & 85 & 67.77 \\
Trade dress & 82 & 67.77 \\
corporate stratgies & 82 & 66.94 \\
Knowledge-based & 81 & 66.94 \\
Models and framework & 81 & 66.12 \\
customers penetration and breadth & 80 & 65.29 \\
corporate method & 79 & 65.29 \\
customers satisfaction & 79 & 64.46 \\
Sales tools & 78 & \\
\hline
\end{tabular}




\begin{tabular}{lcc}
\hline Expert networks and teams & 76 & 62.81 \\
Work-related knowledge & 76 & 62.81 \\
Management processes & 75 & 61.98 \\
Baclog orders & 68 & 56.20 \\
Networking systems & 62 & 51.24 \\
Know-how & 54 & 44.63 \\
Cultural diversity & 53 & 43.80 \\
Management philosophy & 51 & 42.15 \\
\hline \multicolumn{1}{c}{ Item Intellectual Capital Disclosure } & Total sampel & $\mathbf{\%}$ \\
\hline Business collaborations & 50 & 41.32 \\
Favourable contracts & 42 & 34.71 \\
Changebility & 42 & 34.71 \\
Vocational qualification & 41 & 33.88 \\
Price sensitivity & 30 & 24.79 \\
Reactive ability & 30 & 24.79 \\
Research Project & 28 & 23.14 \\
Psychometrics assesment & 27 & 22.31 \\
Reapet business & 21 & 17.36 \\
Financial well beeing & 19 & 15.70 \\
TOTAL & & $\mathbf{1 8 9 1 . 7 4}$ \\
MEAN & & $\mathbf{5 4 . 0 5}$ \\
\hline
\end{tabular}

Berdasarkan Tabel 3 di atas dapat diketahui tingkat rerata Intellectual Capital Disclosure pada perusahaan perbankan size kecil adalah sebesar 54,05. Perbandingan rerata Intellectual Capital Disclosure pada perusahaan perbankan size kecil dengan keseluruhan perusahaan perbankan tidak jauh berbeda. Pada perusahaan perbankan secara keseluruhan tingkat Intellectual Capital Disclosure secara rerata adalah sebesar 58,48 sedangkan rerata tingkat Intellectual Capital Disclosure pada perusahaan perbankan size kecil sebesar 54,05 hanya selisih sebesar 4,43. Hal ini menunjukan pada perusahaan perbankan size kecil akan lebih berusaha untuk menarik minat investor untuk menanamkan modal di perusahaannya untuk meningkatkan total asset yang dimiliki dengan cara melakukan Intellectual Capital Disclosure dengan lebih terperinci. Pada perusahaan dengan size kecil sama halnya dengan sektor perbanakan secara keseluruhan bahwa item corporate value merupakan item yang sering diungkapakan dalam laporan tahunannya.

Tabel 5 di bawah ini menunjukan tingkat rerata Intellectual Capital Disclosure pada perusahaan perbankan size besar adalah sebesar 65,10. Perbandingan rerata Intellectual Capital Disclosure pada perusahaan perbankan size besar dengan keseluruhan perusahaan perbankan tidak jauh berbeda. Pada perusahaan perbanakan secara keseluruhan tingkat Intellectual Capital Disclosure secara rerata adalah sebesar 58,48 sedangkan rerata tingkat Intellectual Capital Disclosure pada perusahaan perbankan size besar sebesar 65,10 hanya selisih sebesar 6,62.

Tabel 5. Frekuensi pengungkapan setiap item Intellectual Capital Perusahaan Size Besar 


\begin{tabular}{|c|c|c|}
\hline Item Intellectual Capital Disclosure & Total sampel & $\%$ \\
\hline & 75 & \\
\hline Management philosophy & 68 & 90.67 \\
\hline Service marks & 61 & 81.33 \\
\hline Information systems & 61 & 81.33 \\
\hline Organization Capital & 61 & 81.33 \\
\hline Financial relation & 61 & 81.33 \\
\hline Corporate values & 61 & 81.33 \\
\hline Trade dress & 60 & 80.00 \\
\hline Sales tools & 60 & 80.00 \\
\hline intangible asset & 60 & 80.00 \\
\hline Management processes & 59 & 78.67 \\
\hline Process capital & 59 & 78.67 \\
\hline corporate stratgies & 59 & 78.67 \\
\hline Knowledge-based & 58 & 77.33 \\
\hline Expert networks and teams & 58 & 77.33 \\
\hline corporate method & 57 & 76.00 \\
\hline Models and framework & 57 & 76.00 \\
\hline customers satisfaction & 56 & 74.67 \\
\hline customers penetration and breadth & 56 & 74.67 \\
\hline Entrepreneurial spirit & 55 & 73.33 \\
\hline Customers & 53 & 70.67 \\
\hline Work-related knowledge & 53 & 70.67 \\
\hline Baclog orders & 49 & 65.33 \\
\hline Know-how & 47 & 62.67 \\
\hline Research Project & 40 & 53.33 \\
\hline Networking systems & 39 & 52.00 \\
\hline Business collaborations & 38 & 50.67 \\
\hline Vocational qualification & 38 & 50.67 \\
\hline Favourable contracts & 35 & 46.67 \\
\hline Cultural diversity & 35 & 46.67 \\
\hline Changebility & 33 & 44.00 \\
\hline Psychometrics assesment & 30 & 40.00 \\
\hline Reapet business & 26 & 34.67 \\
\hline Reactive ability & 24 & 32.00 \\
\hline Financial well beeing & 23 & 30.67 \\
\hline Price sensitivity & 19 & 25.33 \\
\hline TOTAL & & 2278.67 \\
\hline MEAN & & 65.10 \\
\hline
\end{tabular}

Selisih tersebut menunjukan bahwa pada perusahaan perbankan size besar, tingkat Intellectual Capital Disclosure pada perusahaan perbankan size besar lebih tinggi jika dibandingkan perusahaan size kecil dan juga perusahaan secara keseluruhan adalah 
sangatlah memungkinkan. Perusahaan dengan size besar akan mengungkapkan informasi mengenai Intellectual Capital Disclosure secara lebih lengkap untuk menunjukan aktivitas tinggi mereka, baik aktivitas operasional maupun aktivitas administratif, yang menyebabkan asset perusahaan meningkat.

Pada perusahaan size besar, frekuensi tingkat pengungkapan setiap item Intellectual Capital Disclosure tertinggi adalah management philosophy. Management philosophy merupakan seperangkat keyakinan dasar yang menjadi parameter bagi seluruh elemen perusahaan (menggambarkan apa yang seharusnya dikerjakan dan yang tidak dikerjakan oleh perusahaan). Selain itu, perusahaan dengan ukuran yang besar lebih mendapat perhatian yang besar dari pasar sehingga mereka cenderung untuk melakukan Intellectual Capital Disclosure agar dapat memberikan value added bagi perusahaan. Sehingga, perusahaan semakin dituntut untuk lebih melakukan transparansi.

Pada perusahaan size besar, frekuensi tingkat pengungkapan setiap item Intellectual Capital Disclosure tertinggi adalah management philosophy. Management philosophy merupakan seperangkat keyakinan dasar yang menjadi parameter bagi seluruh elemen perusahaan (menggambarkan apa yang seharusnya dikerjakan dan yang tidak dikerjakan oleh perusahaan).

\section{PENUTUP}

Simpulan. Praktik Intellectual Capital Disclosure dalam annual report pada perusahaan perbankan di Indonesia dengan menggunakan weighted index menunjukan nilai rerata sebesar 58,48\% dari total keseluruhan item Intellectual Capital Disclosure. Berdasarkan data tersebut maka dapat disimpulkan bahwa kesadaran perusahaan perbankan di Indonesia akan pentingnya Intellectual Capital sudah cukup baik. Rerata ini mengalami peningkatan sebesar 24,48\% dari hasil penelitian Suhardjanto dan Wardhani (2010). Hal ini menunjukan bahwa narrow financial based stakeholders membutuhkan banyak informasi tentang Intellectual Capital untuk memperoleh jaminan yang berkaitan dengan kepentingan mereka dalam perusahaan. Selain itu, pasar lebih bereaksi terhadap perusahaan yang mengungkapkan informasi penting terutama bagi kepentingan stakeholders, diantaranya adalah Intellectual Capital Disclosure. Transparansi yang diberikan oleh perusahaan akan direspon oleh pasar sehingga akan meningkatkan value added serta competitive advantage bagi perusahaan. Oleh karena itu, praktik Intellectual Capital Disclosure di Perbankan Indonesia. Tingkat praktik Intellectual Capital Disclosure pada perusahaan size besar, cukup baik yaitu berkisar sebesar 65\%. Perusahaan perbankan dengan size besar, lebih mendapatkan perhatian yang besar dari pasar sehingga mereka cenderung untuk melakukan pegungkapan atas Intellectual Capital yang dimilikinya, sehingga menambah value added dan competitive advantage bagi perusahaan (Purnomosidhi, 2006; Bukh; Nielsen; Gormsen; \& Mouritsen, 2005). Perusahaan size kecil menunjukan tingkat praktik Intellectual Capital Disclosure yang cukup baik yaitu sebesar $62 \%$ melebihi $2 \%$ dari perusahaan perbankan secara keseluruhan.

Saran. Penelitian ini menggunakan narrow financial based stakeholders untuk melihat frekuensi kepentingan ICD. Penelitian selanjutnya dapat menggunakan klasifikasi stakeholders selain narrow financial based stakeholders, misalnya virtue based, duty based dan right based. 


\section{DAFTAR RUJUKAN}

Abeysekera, I dan Guthrie, J. (2005) "An Empirical Investigation of Annual Reporting Trends of Intellectual Capital in Sri Lanka". Critical Prespectives in Accounting, 16(3), 151-163.

Bontis, Nick. (2002) "Intellectual Capital Disclosure in Canadian Corporation". Journal Of Human Resource Costing and Accounting

Bozzolan, S; F. Favotto, dan F. Ricceri, (2003) "Italian annual intellectual capital disclosure; An empirical analysis". Journal of Intellectual Capital. 4(4), 543-558.

Brooking, A. (1996) Intellectual Capital, Thomas Business Press, London.

Brown, AM; Tower, G; and Taplin, R. (2004) Relationship between type of user respondent and stakeholders groups in the contex of pacific island countries. Research in Accounting in Emerging Economics, Supplement 2: Accounting and Accountability in Emerging Economics, Supplement 2: Accounting and Accountability in Emerging and Transition Economics: 469-502.

Bukh, P.N; C.Nielsen; P. Gormsen, dan J. Mouritsen, (2005) "Disclosure of information on Intellectual Capitalin Danish IPO prospectuses", Accounting, Auditing \& Accountability Journal. 18(6),713-732.

Cerbioni, F. dan A. Parbonetti, (2007) Exploring the effect of Corporate Governance on Intellectual capital Disclosure: An Analysis of European Biotechnology

Deegan, C. And Bloomquist, C. (2006) Stakeholders Influence on Corporate Reporting: An Expolration of Interaction betwee WWF Australian and Australian Minerals Industry, Accounting Organiztions and Society, 31: 343-372.

Eccles, R.G; R.H. Herz; KeenandanD.M. Phillips. (2001) The Value Reporting Revolution. Moving Beyond The Earnings Game. John Willey and Sons, New York.

Edvinsson, L.,danM.S. Malone, (1996) Intellectual Capital: Realizing Your Company's True Value by Finding Its Hidden Roots, Harper Collins Publishers, Inc., New York.

Edvinsson, L., (1997). "Developing Intellectual Capital at Skandia". Long Range Planning, 30 (3), 366-373.

Edvinsson, Leif dan Sullivan, P. (1996) "Developing Model for Managing Intellectual Capital". European Management Journal, 14 (4), 356-364.

Firer, S. dan S.M. Williams, (2003) "Intellectual capital and traditional measures of corporate performance", Journal of Intellectual Capital, 4(3), 348-360.

Ghazali, N.A.M., Haji, A.A. (2013) "A longitudinal examination of intellectual capital disclosures and corporate governance attributes in Malaysia". Emerald Group Publishing Limited.

Guthrie, J. and R. Petty, (2000) "Intellectual Capital: Australian annual reporting practices". Journal of Intellectual Capital. 1(3).

Guthrie, J., dan I. Abeysekera. (2006) An Empirical Investigation of Annual Reporting Trends of Intellectual Capital in Sri Lanka, Critiscal Perspective on Accounting.

Harrison, JS dan Freeman, RE. (1999) "Stakeholders, social responsibility, and performance: empirical evidence and theoretical prespectives". Academy of Management Journal, 42 (5), 479-485.

Harisson , S., dan P.H. Sullivan. (2000) "Profiting from intellectual capital; Learning from leading companies". Journal of Intellectual Capital. 1 (1), 33-46. 
Hidalgo, R.L; E.G. Meca, dan I. Matinez, (2011) Corporate Governance and Intellectual Capital Disclosure: Evidence from Italian Listed Companies. Department of Business Administration.

Li, J;R. Pike, dan R. Haniffa, (2008) "Intellectual Capital Disclosure and Corporate Governance Structure in UK Firms". Accounting and Business Research, 38 (2), 137-159.

Oliveira, L; L.L. Rodrigues, dan R. Craig, (2008) Applying Voluntary Disclosure Theories to Intangibles Reporting: Evidence from the Portuguese Stock market. www.ssrn.com.

Purnomosidhi, B., (2006) "Praktik Pengungkapan Modal Intelektual Pada Perusahaan Publik di BEJ". Jurnal Riset Akuntansi Indonesia. 9(1),1-20.

Roos, J; G. Roos; N.C. Dragonetti, danL. Edvinsson. (1997) Intellectual Capital Navigating The New Business Landscape, London; MacMillan Press Ltd.

Suhardjanto, D., Tower G., dan Brown., A.M. (2007) "Generating A Uniquely Indonesian Enviromental Reporting Disclosure Index Using Press Converage as An Important Proxy of Stakeholder Demand". Paper Submission to Asia Academic Accounting Association Annual Conference Yogyakarta. Indonesia.

Suhardjanto, D., dan M. Wardhani, (2010) "Praktik Intellectual Capital Disclosure Perusahaan yang terdaftar di BEI", Jurnal Akuntansi dan Auditing Indonesia. 14 (1).

Sveiby, K.E., (1997) The New Organizational Wealth: Managing and Measuring Knowledge-based Assets, San Fransisco. CABerrett-Koehler Publishers.

Ullman, AA. (1985) "Data in search of a theory: a critical examination of the relationships among social performance, social disclosure, and economics, and economics performance of U.S firms". Academy of Management Review, 10(3), 540-557.

Yi An dan H.Davey. (2010) "Intellectual capital disclosure in Chinese (mainland) companies". Journal of Intellectual Capital.11(3), 326-347. 